\title{
A Many-Valued Empirical Machine for Thyroid Dysfunction Assessment
}

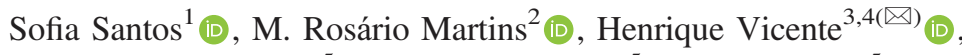 \\ M. Gabriel Barroca ${ }^{5}$ (D) , Fernando Calisto ${ }^{5}$ (D) , César Gama ${ }^{5}$ (D), \\ Jorge Ribeiro $^{6}$ (D) Joana Machado ${ }^{7}$ (D), Liliana Ávidos ${ }^{8}$ (D), \\ Nuno Araújo ${ }^{8}$ (D), Almeida Dias $^{8}$ (D), and José Neves ${ }^{4}$ (D) \\ ${ }^{1}$ Departamento de Química, Escola de Ciências e Tecnologia, \\ Universidade de Évora, Évora, Portugal \\ 2 Departamento de Química, Escola de Ciências e Tecnologia, \\ Laboratório HERCULES, Universidade de Évora, Évora, Portugal \\ ${ }^{3}$ Departamento de Química, Escola de Ciências e Tecnologia, \\ Centro de Química de Évora, Universidade de Évora, Évora, Portugal \\ hvicente@uevora.pt \\ ${ }^{4}$ Centro Algoritmi, Universidade do Minho, Braga, Portugal \\ jneves@di.uminho.pt \\ ${ }^{5}$ SYNLAB Alentejo, Évora, Portugal \\ ${ }^{6}$ Escola Superior de Tecnologia e Gestão, ARC4DigiT - Applied \\ Research Center for Digital Transformation, \\ Instituto Politécnico de Viana do Castelo, \\ Viana do Castelo, Portugal \\ ${ }^{7}$ Farmácia de Lamaçães, Braga, Portugal \\ ${ }^{8}$ CESPU, Instituto Universitário de Ciências da Saúde, Gandra, Portugal
}

\begin{abstract}
Thyroid Dysfunction is a clinical condition that affects thyroid behaviour and is reported to be the most common in all endocrine disorders. It is a multiple factorial pathology condition due to the high incidence of hypothyroidism and hyperthyroidism, which is becoming a serious health problem requiring a detailed study for early diagnosis and monitoring. Understanding the prevalence and risk factors of thyroid disease can be very useful to identify patients for screening and/or follow-up and to minimize their collateral effects. Thus, this paper describes the development of a decision support system that aims to help physicians in the decision-making process regarding thyroid dysfunction assessment. The proposed problem-solving method is based on a symbolic/sub-symbolic line of logical formalisms that have been articulated as an Artificial Neural Network approach to data processing, complemented by an unusual approach to Knowledge Representation and Argumentation that takes into account the data elements entropic states. The model performs well in the thyroid dysfunction assessment with an accuracy ranging between $93.2 \%$ and $96.9 \%$.
\end{abstract}

Keywords: Thyroid dysfunction $\cdot$ Knowledge Representation and Reasoning • Artificial Neural Networks · Entropy · Logic Programming • Many-Valued Empirical Machine 